\title{
The Weight Attached to Dieting: Health, Beauty and Morality in Sweden from the End of the Nineteenth Century to the Present Day
}

\author{
By Pia Lundquist Wanneberg
}

\begin{abstract}
Over the last hundred years a new ideal body norm has been established. We should be thin, or at least strive to be. Consequently, dieting has become a topical subject. This article aims to examine the history of Swedish dieting from the introduction of William Banting's diet into Sweden at the end of the nineteenth century to the present day. The article takes tries to answer the following questions: Why did people diet? Was it for aesthetic, social or health reasons? Or was it a physical expression of good morality in the form of self-discipline and control? The theoretical basis of this study is inspired by Michael Foucault's concept of biopower and the study method is a qualitative text analysis done by examining medical books and weekly newspapers. The findings show that a strong argument for dieting was the health risks which corpulence was deemed to be linked to. But there were moral, aesthetic and psychosocial reasons too. All these reasons appeared, to a lesser or greater extent, in both medical books and weeklies during the whole period. Aesthetic reasons, however, featured most prominently in weeklies, whereas medical books devoted most space to health reasons. When discussing the latter, physicians, often, however, strayed onto moral reasons. Highlighted as the psychosocial reason were the derision and insults corpulent people endured, which made their lives miserable because they could not participate in society in the same way as thin people. In this context, dieting was portrayed as little short of a miracle. If only an overweight person became thin, their life would change and they would be happy. There is such an abundance of these dieting stories in weeklies that they constitute their own genre.
\end{abstract}

\section{Keywords: Dieting, Body norm, History, Biopower, Qualitative text analysis}

Over the last hundred years or so, a new ideal body norm has been established: we should be thin or at least strive to be. As a consequence of the new body ideal, dieting became a topical subject and still is with the new dietary advice and miracle diets we are continually being fed. The history of dieting can, however, be traced back to at least ancient Greece and even to the Christian ideals of controlled eating and fasting (Foxcroft 2011). At that time, people were not, however, dieting as we know it but adhering to a diet for medical, moral and/or religious reasons; gluttony was a sin, and starvation could put people, especially young women, in contact with God. During the nineteenth century, however, the meaning of adhering to a diet changed to include also dieting (Stearns 1997), whose popularity can actually be dated to 1863, when the Englishman William Banting published Letter on Corpulence. To be sure, the negative consequences of corpulence had been observed earlier in Europe but without garnering much attention, the reason being corpulence was associated with status, and thinness with starvation and poverty (Vester 2010). However, it seems the time was ripe for Banting's work.

Banting had been corpulent, and his pamphlet aimed to help others in the same predicament. What set the pamphlet apart was it contained a plan, a course

\footnotetext{
*Associate Professor, The Swedish School of Sport and Health Sciences, Sweden.
} 
of treatment, in which dieting was an end in itself. The course of treatment proved hugely successful, spreading across Europe and to the United States and giving birth to "dieting," a new word for "weight reduction" (Zweiniger-Bargielowska 2010). Nowadays, the notion exists that dieting is particularly a women's issue, caused by an ever-thinner body ideal, which research has also highlighted (see, for example, Bordo 1993, Sobel and Maurer 1999, Stinson 2001). However, Banting's target group was British middle-class men. His course of treatment embraced food such as red meat and alcohol, which were linked to masculinity and economic prosperity. Moreover, the slimmed-down body was in keeping with the contemporary middle-class male ideals of discipline and self-control. Women were therefore not initially included; however, middle-class women first became involved when dieting was an established male activity (Vester 2010). It would appear that at the turn of the twentieth century working-class women did not suffer from obesity; if anything, it was the opposite given the then food tradition, at least in British working-class homes, where the man as the breadwinner ate first, followed by the children and lastly the woman (Zweiniger-Bargielowska 2010).

Banting's pamphlet, as already mentioned, spread throughout the Western world, including Sweden. The question is how was Banting's concept received and developed. The article aims to examine precisely this, with the focus on why did people diet. Was it for aesthetic, social or health reasons? Or was dieting a physical expression of good morality in the form of self-discipline and control? Did the reasons change over time and, if so, in what way?

\section{Literature Survey}

In international research on dieting, the main focus is on obesity. One such study is Hillel Schwartz's Never Satisfied: A Cultural History of Diets, Fantasies and Fat, which has to be regarded as a standard work in the field. The study spans just over 150 years and examines the American obsession with obesity and diets in relation to the new body ideal that arose with the growth of the consumption society at the end of the nineteenth century. Its thesis is that obesity began at this time to undergo a transformation, from having indicated esteem and respect to being regarded as a disease. Since then, the country has seen many diet fads, with dieting having become part of American society (Schwartz 1986). Schwartz sees the growth of, for example, the fashion industry, the marketing of goods and services, and medical technology, for instance modern society's increasing fixation with measuring things, as the underlying reasons for this. Here people's weight came to serve as an index of character as well as health and beauty.

Obesity in America is also a central theme of Peter N. Stearns' Fat History: Bodies and Beauty in the Modern West. Stearns, however, makes a comparison with France based on America being the most obese nation in the Western world and France the thinnest. How the French and the Americans viewed obesity changed during the twentieth century, but their reasons for not being overweight differed. While the French were thin for health and beauty reasons, moral aspects 
dominated in America (Stearns 1997). Stearns explains the new thinner body ideal as being cultural. According to him, only cultural factors, for example the consumption, beauty and morality culture, can explain how the two countries developed and differed. He does not, however, discuss what culture is and how cultures are changed.

The British author Louise Foxcroft's book Calories \& Corsets: A History of Dieting over 2,000 Years discusses, among other things, diets as well as shortcuts and methods for at least looking thin: everything from corsets and rubber underwear to laxatives and strychnine (Foxcroft 2011). The long period covered, however, produces a rather general and epic picture of the subject and does not answer why it was important to look thin or lose weight. A more theory-driven British study is Managing the Body: Beauty, Health and Fitness in Britain, 1880 1939, by Ina Zweiniger-Bargielowska. This study examines training and weight control in relation to the male body's physical degeneration, deemed to have taken place at the beginning of the twentieth century and viewed as a threat to Britain's powerful position (Zweiniger-Bargielowska 2010). The book's focal point is the relationship between the citizens' bodies and the bodies the governments wanted to see, which Zweiniger-Bargielowska studied by looking at the health education campaigns. For instance, male obesity first needed to be tackled, and not long after, female obesity.

In Swedish studies, too, the focus is more on overweightness and obesity than on dieting, even though the subject is touched upon. In the study I ett bolster av fett [In a Cushion of Fat], Fredrik Nilsson examines obesity in relation to masculinity and class, to be more precise an analysis of the transition from a rotund peasant ideal to a thinner middle-class variant. Nilsson shows that during the nineteenth century overweightness in men was slowly but surely defined as a problem by principally the medical profession and in medical research but also by various social commentators (Nilsson 2011). According to Nilsson, the view was reinforced in the twentieth-century Swedish welfare state when overweightness went from being seen as a middle-class problem to being categorised as a national disease. Not only the government but also organisations were involved in the fight against the flab. The 1940s saw the establishment of, for example, Föreningen Fetmans Fiender (The Association of the Enemies of Obesity), which, according to Nilsson, acted as a national bulwark against the consequences of overweightness for the individual and society. The association (active until 2012) focused on physical activity in the form of, for instance, gymnastics, swimming as well as saunas. Private actors gradually replaced organisations; one well-known example is the American company Weight Watchers, which established itself in Sweden in the 1970s.

Obesity, from a societal perspective, is also the theme of Helena Sandberg's Medier \& fetma: en analys av vikt [Media \& Obesity: An Analysis of Weight]. More specifically, her study examines how overweightness was represented in four Swedish daily newspapers between 1997 and 2001 as well as what values and norms were produced and reproduced in these newspapers (Sandberg 2004). The study also presents examples of numerous dieting methods in the form of medicines, exercises and diets. The findings show, among other things, that 
overweight people were stigmatised, and unlike Banting, who wanted to help his fellow overweight brethren, even formerly overweight people were involved in the stigmatising. However, overweight men were not described as negatively as their female counterparts; instead, the former's overweightness and failings were overlooked. The newspapers thus did not show this tolerance towards these women, who, instead, were depicted as disgusting, unsuccessful and even detestable.

To sum up, there are some general and more descriptive international historical studies on dieting. Of the Swedish studies, only Nilsson's has a longer historical perspective, which will be expanded on here to include women. Moreover, a clearer power perspective on the historical development will be introduced. ZweinigerBargielowska's study is the only one with both a longer historical perspective and a power perspective. Like this study, it takes Michel Foucault's concept of biopower as its theoretical starting point.

\section{Power over Life}

For Foucault, power is, as we know, not something absolute that someone possesses but something exercised. And since it is always exercised within a relationship, power is per definition relational. This goes for important social relationships, such as between work and capital or between politicians and voters, as well as at a lower level, for example between men and women, parents and children or doctors and patients. We are all involved in countless relationships where power is exercised; we cannot opt out because it is always there. Since power is not a resource that resides in a certain position, it is difficult to narrow down and examine, but it can be acquired through the techniques employed when it is being exercised. Foucault distinguishes between sovereign power, disciplinary power and biopower. An important difference between sovereign power and biopower is that the latter focuses on preserving and protecting life instead of taking life. Nor does disciplinary power operate through public violence; however, unlike biopower, which targets large groups of people, the individual is the focus. It is the individual who is supervised, controlled and trained to be an obedient and compliant subject. These various forms of power occurred in different societies, but Foucault is not entirely clear whether they replaced each other. Plausible interpretations have been put forward, namely they complement each other by, among other things, operating at different societal levels (see, for example, Lilja and Vinterhagen 2014, Harwood 2009).

Typically for Foucault, he links power with the body, which is subjected to painful punishments, discipline and correction or self-disciplining in the form of training, dieting or plastic surgery. Because Foucault views power as productive, the body mirrors the power. More specifically, power is, as already mentioned, exercised through various kinds of techniques (acts) to which various technologies (knowledge) are connected. Foucault (1980: 52; as cited in Nilsson 2008) states that "it is not possible for power to be exercised without knowledge, it is impossible for knowledge not to engender power." In other words, power and knowledge are 
intrinsically linked and presuppose each other. However, power, according to Foucault, not only creates knowledge; it also produces individuals who are a product of power - how they see and perceive themselves, how they see others and how they are seen and understood by others. What gives the productivity of power its legitimacy is that, along with being prohibitive or inhibitory, it also has advantages for the individual: better health, living longer, etc. While steering the population towards becoming stronger and more capable, power produces something perceived as good. The greater freedom we enjoy today does not mean we are not steered but just differently. Power and freedom are co-constitutive.

Biopower, or power over life, is thus a productive power organised around norms that cause an individual's actions. People's lives and behaviours are analysed, controlled and governed by technologies and techniques. However, biopower's aims are not confined to the individual; it targets the whole of, or sometimes sections of, a population of, for example, a country, an organisation or an institution (Lilja and Vinterhagen 2014). Biopower is seldom exercised directly by the state but through actors such as doctors, dieticians and gym instructors, rather often as written exercise advice, healthy recipes or recommended checkups. With the scientific knowledge and the administrative techniques these actors have developed, people's behaviours and lives are defined, controlled and governed. It is an organised influence on behaviour in relation to the objectives designed to improve, for example, our hygiene, level of health and lifespan (Coll 2013).

In this study, dieting is seen as a technique for regulating and steering people's behaviour and lives in a certain direction. The question is in which direction: is it their health, morality or something else?

\section{Method and Source Material}

The methodology used is a qualitative text analysis, that is to say, a systematic qualitative analysis of primary data collected from various types of texts (Denzin and Lincoln 2008). In this case, it is qualitative since conceptions, experiences and ideas expressed in the collated texts have been observed. Analysing qualitative data requires an understanding of how to make sense of texts so you can answer your research questions. Here the analysis has involved a careful reading and rereading of all the material in order to pinpoint the key themes of the texts in relation to the aim and research questions. In this process, I have first looked for the texts' patterns by identifying meaning units in the form of conceptions and ideas. The patterns were then aggregated into larger themes (Cresswell 2012).

To make sense of the findings, qualitative studies also require a preunderstanding of the examined phenomenon; that is the key to comprehension and interpretation (Denzin and Lincoln 2008). In this instance, the pre-understanding is previous research in the field and Foucault's concept of biopower.

This study takes a historical approach. As a historian, you cannot create your own data, so you have to analyse the available remnants. Here the source material comprises medical books, weekly magazines and a health magazine; together they 
span the end of the nineteenth century to the present day. The weekly magazines are Idun, whose target group was middle-class women, and Aret Runt, a family magazine with a broad readership. Idun was published between 1887 and 1963, when it merged with another magazine. Aret Runt was first launched in 1946 and is still in publication. Health magazines are a fairly new phenomenon, but the one included here is Må bra, which first hit the shelves in 1976. It has today the highest circulation figures of all health magazines in Sweden. Every issue of Idun, Arret Runt and Må bra has been examined, starting with their first year of publication and then every fifth year.

Medical books were used as source material because of the medical profession's increasingly powerful position during this period. Moreover, it is through the pages of these books that the medical profession communicates with the public. I have examined all Swedish-language medical books that during this period discussed dieting. The weekly magazines and the health magazine are important source material for finding out what was being debated in Swedish society and in what way. The media convey values and attitudes and inform us of what is expected of us and what we can expect of others. The media can be said to act as a compass - rather often a moral one - that helps us navigate life. Nowadays we talk about mediated experiences, that is to say, ones we have acquired from the media and made into our own when we have no personal experience of the subject in question (Thompson 1995, Cotter 2001). So even if the reader has never been overweight or dieted, they can acquire through the media both experiences of the subject and an idea of what we can expect of people who are overweight and/or dieting.

\section{The Findings}

\section{How Banting Was Received in Sweden}

Banting, 65 years old when Letter on Corpulence was published, had, in his own words, long suffered from obesity, which had hugely affected his life. For example, he had been unable to take off his shoes, stoop or go down the steps normally; instead, he had to go down backwards, an exertion causing him to sweat profusely and become seriously out of breath. Moreover, when in train compartments and theatre auditoriums, he felt he terrified those around him. Preferring to stay at home than to be ridiculed and scorned, he became socially isolated and low-spirited: "Of all the parasites that affect humanity I do not know of, nor can I imagine, any more distressing than that of Obesity" (Banting 1864).

Banting had made numerous attempts to lose weight. He had tried to be physically active and had taken various kinds of baths believed to have weightreducing effects. He had also sought the advice of many eminent physicians in this field, but without any luck. Help came from an unexpected quarter, from an ear, nose and throat specialist named William Harvey. Banting's hearing had deteriorated; hence, he consulted Harvey, who felt Banting's deafness was linked to his corpulence. He prescribed the diet that Banting reproduces in Letter on 
Corpulence. Harvey's source of inspiration for this diet was a lecture he had heard the French physiologist Claude Bernard give on the role liver played in cases of diabetes. Bernard believed that, apart from secreting bile, the liver produced something that helped to break down sugar. Harvey began to examine how various kinds of food, including carbohydrates, affected the body (Gilman 2008). A reduction in carbohydrates was central to the diet Banting was on: carbohydrate foods, such as bread, sugar and potatoes, were eliminated as were beer and milk. Instead, his meals consisted principally of meat but also fish, vegetables as well as servings of wine, sherry or Madeira to accompany his lunches and dinners. Banting claimed that thanks to this diet he had lost in the first year 46 pounds (approx. 21 kilos). His health and his life in general had, also according to himself, considerably improved (Banting 1864, Gilman 2008).

In 1864, Banting's pamphlet, published the previous year, was the subject of a letter printed in a Swedish newspaper. The letter described, praised and criticised his method. The writer, who himself suffered from corpulence, had given Banting's diet a go for a month. Thanks to his endeavours, he felt "fleeter of foot" for the first time in twenty years, he no longer needed a siesta, he felt young again and had lost weight. But, he wondered, was it really possible to equate weight with health? Might the huge meat intake, combined with a reduced fat intake, create an unhealthy imbalance in the body? He also questioned the large quantities of alcohol that were part of the treatment; besides wine with every meal, he took a whisky nightcap. Could the health benefit that a weight reduction might bring compensate for what was verging on drunkenness (Post-och Inrikes Tidningar 1864)?

Two years later, in 1866, Letter on Corpulence was translated into Swedish by Edward Edholm, physician and member of the Royal Medical Board. In 1880, Edholm evaluated the method, which, in his opinion, had been well-received by the medical profession and the general public, both in Sweden and abroad. The question "Do you bant?" entered public discourse in England just like the verb "banta" did in Sweden. Edholm himself was wholly in favour of the method and wished to help spread the word. One thing Edholm very much liked to emphasise was that Banting's treatment was based on science, and he immersed himself in, and described in detail, the chemical and physiological processes involved when following the diet and which foods were suitable and unsuitable when doing so (Edholm 1880).

Why then, according to Edholm, should people diet? He listed many reasons, but the main ones were health-related. Overfatness, known as morbidly obese, was associated with a number of health risks, principally due to the fat deposits not just between the skin and the muscles but also in the inner muscles, arteries and organs. All the fat made it harder for the heart to pump the blood around the body, and with fat also pressed up into the thoracic cavity, the lungs were negatively affected as well. Consequently, the sufferer had palpitations, difficulty breathing and chest pressure as well as bad eyesight and hearing problems. In fact, no body part was unaffected. In the case of women, who, according to Edholm, were more inclined to be obese than men, even their reproductive organs were affected, which could cause hysteria and sterility. The prognosis was bleak for obese people: 
"Afflicted with these troublesome symptoms, overfat people live a wretched existence until a supervening disease or the rampancy of overfatness ends their suffering." (Edholm 1880: 42; my translation)

Besides health reasons, Edholm put forward other reasons why obese people should diet. One was aesthetic-related. For, according to Edholm, obese people's body parts were not in harmony. The slender and curved contours, which, in his opinion, were the foundations of health and beauty, were instead bulky and unsymmetrical. For example, the head was either flushed or, like the rest of the skin, "pale, flabby and puffy." With the throat covered by a thick layer of fat, the chest looked thinner than usual, and the lower abdomen protruded, which, in turn, affected the person's gait in an unflattering way (Edholm 1880). Edholm's notions about equating beauty with a harmonious body can be traced back to that period's natural philosophical notion of interconnectedness. Because a human being is made up of a number of parts, it could not be completely whole; the wholeness depended on the relationship between body parts. Being in harmony was a sign of both beauty and health, and disharmony the opposite (Ljunggren 1999). As for Edholm, who, of course, was a physician, the health reasons he gave for dieting were probably linked to the natural scientific ideals, but he shared the aesthetic notion held by the nature romanticists, namely obesity meant a departure from the ideal of the harmonious whole and was therefore ugly.

The other reasons Edholm gave for dieting were moral-related. He described three real-life cases designed to be inspiring and edifying: three overweight Swedish men who had lost weight thanks to Banting's treatment. In the case descriptions, he emphasises the effort of will and the firmness of character that had produced the successful results. On the other hand, he described those who failed to complete the treatment as weak people undeserving of compassion. They had only themselves to blame if they were ridiculed and parodied. The three men also demonstrated a scientifically critical approach to their dieting insofar as they tested various foods to see whether they put on or lost weight. They added a few glasses of beer a week, then weighed themselves; they slightly reduced the number of glasses and weighed themselves again (Edholm 1880). Taking a scientific approach to dieting appears almost as important as the actual weight reduction.

The three cases are interesting from another perspective. According to Edholm, he had chosen to publish these very cases because they were representative and served as good examples for those wanting to lose weight. Interestingly enough, they are all middle-aged, middle-class men. Besides, as shown above, women's specific obesity problems, Edholm makes no mention whatsoever of women. As for other social classes, he noted that farmers and craftsmen were thin even though they ate copious amounts due to the heavy work they did, and although the poor, working-class population's food was mainly, according to Banting's treatment, unsuitable, such as bread, potatoes, milk and porridge, this group rarely had overweight people (Edholm 1880).

Banting's treatment thus appears to have aroused the interest of middle-class Swedish men even though the diet came in for some criticism. Above all, health reasons, but also moral and aesthetic ones, were given for why people should diet. 
These reasons were to continue to be invoked. However, Edholm fails to give the perhaps most prominent reasons advanced by Banting himself: the psychosocial ones. For Banting, his corpulence had caused him to become isolated because of the ridicule received and the problems he had getting around outside. This will also be further examined later in the article.

\section{"The Fat Person is digging their own Grave with their Teeth"}

From having been a sign of good health, obesity, as already mentioned, began to gradually be viewed as a disease, meaning it was the physician's job to diagnose and treat the condition. At the turn of the twentieth century, physicians categorised obesity into two types based on a difference of degree: morbid obesity, known as overfatness, and non-morbid obesity, known as corpulence. Three criteria were used to ascertain whether a person suffered from morbid obesity. The first one concerned their appearance: that the person in question's body size and girth harmed the body's proportions. A large weight increase was only the second criterion, and the third was the functional changes of certain organs. To be diagnosed as overfat, the patient had to fulfil all three criteria (Pfannenstill 1901). However, gradually a person's weight in kilos, followed by their body mass index (BMI) and then their waist and belly size, determined whether they were overfat. For example, a person's BMI is used today as a criterion for determining whether they receive a gastric bypass (Lagerlöf 1958, Hasselgren 2013). Defining a person's condition does not appear to have been that easy. During the research period, the medical books interchangeably used the terms overfatness, obesity, morbid obesity and corpulence to describe the condition, with obesity being the most common.

Just as with Edholm, the medical profession held the view throughout the research period that obesity could cause numerous minor and serious complications. What changed over time, however, was how obesity was viewed, and, from a health perspective, what it caused. The medical books warned that an overweight person who did not tackle this and go on a diet could be afflicted with complaints, such as flat-footedness, articular cartilage damage in the knees and varicose veins, thus causing the person pain, which, in turn, restricted their mobility, as a result of which they could put on some extra kilos. Moreover, the patient could exhibit eczema-like changes in the rolls of fat but also serious diseases, such as heart problems, a stroke and cancer (Sjövall 1953, Dickstone 1948, Åberg, 2005, Hasselgren 2013). This was quite clearly linked to the many dangers of being overweight, or as one physician in the 1950s put it: "The fat person is digging their own grave with their teeth" (Sjövall 1953: 91; my translation).

At the beginning of the 1950s, at any rate, dieting had in Swedish society spread from middle-class men to other social classes and women. The media observed at the time that increased prosperity had resulted in the Swedish population getting fatter. A survey conducted by the Swedish Gallup Institute in 1951 found that 42 per cent of women felt they were fat, and 25 per cent were dieting. The numbers were lower for men, with 17 per cent feeling they needed to 
lose weight (Bolling 2005). Further proof that the beginning of the 1950s had seen a change is that ads for weight-gain preparations for thin people disappeared from the pages of the weekly magazines while ads for various slimming preparations increased. The United Kingdom witnessed a similar trend. With food becoming cheaper during the second half of the twentieth century, obesity spread down through the social hierarchy (Zweiniger-Bargielowska 2010).

During the 1950s, medical books began to even view obesity as a psychological problem with regard to why people were overweight and why it was so hard to diet. Food was described as comfort or a substitute for something missing in life. This comfort eating was deemed something women particularly did given that they spent a lot of time at home and therefore always had food at hand. It was "so easy to go into the pantry and take something delicious when she wants to brighten up her day a bit" (Ahltorp and Kühnel 1956: 373; my translation). Women were, however, also affected in another way, more precisely in their parental role: "Even if it is unclear where overfatness comes from, a specific reason can sometimes be given. It is the mother." The mothers taught their children to comfort eat by giving them food instead of encouragement or comfort (Sjövall 1953: 79; my translation). "She abreacts anxiety and excessive love, disappointments and difficulties by stuffing the child with food" (Karup 1956: 11; my translation). This specific responsibility for the child's future risk of becoming overweight continued until at least the end of the twentieth century. Overweight women posed a threat not only to themselves but also to future generations because they controlled children's eating habits.

Even in the weekly magazines, health risks frequently featured as a reason why people should diet. Until the 1970s, however, there were few articles on dieting. Prior to then, the dieting-related content was principally ads for various preparations and "Ask the Doctor" columns. The 1980s saw a marked increase in the number of articles on dieting, reaching its peak around the turn of the twentyfirst century, when they featured in practically every issue. The health aspects of dieting resemble the ones presented in the medical books. Obesity was associated with health risks, such as high blood pressure, cardiac infarction, diabetes and back pain. People attested that physicians had even warned them that they would not live particularly long if they did not start to lose weight (see, for example, Aret Runt, no. 24, 1960 \& no. 17, 1976).

During the 1970s, celebrities started to be used to give dieting a boost. They were part of a specific dieting genre found in the weekly magazines. Characteristic of the genre was a person, preferably well known, but not necessarily the case, gaining the readers' sympathy by recounting how terrible their overweight life had been and how great they felt after losing weight. Along with "shedding" the kilos, they had lowered their blood pressure and lipids, their insulin levels had returned to normal, their heart was functioning better, and their knees had stopped aching. They went from living more or less in torment to feeling - after their diet confident about the rest of their life. The transformation, however, did not happen by itself; instead, they had to fight and battle and be single-minded, which eventually paid off (see, for instance, Året Runt, no. 23, 1991 \& no. 3, 2016). 
Towards the end of the period, we can see, however, the argumentation for dieting is mainly no longer linked to the reasons. The focus now was on finding a suitable diet or form of exercise. Dieting appears to have become self-evident, something people did without external influence. Instead of encouraging dieting, the weekly magazines' task was now to offer a wide variety of individually tailored exercise programmes and diets.

\section{Fat, Stupid and Costly}

A powerful reason for dieting was therefore the health risks that obesity was believed to be associated with; however, there were also moral reasons. Dieting required so-called good characteristics, such as patience and willpower, and being corpulent indicated a lack of these. The corpulent person was, according to some physicians, totally to blame for their predicament, and therefore they could only tackle obesity if they had overcome weaknesses, such as a craving for pleasure and laziness (see, for example, Josefson and Tillgren 1928, Karup 1956, Pfannenstill 1901). In keeping with this, it was not uncommon for physicians to describe unsuccessful dieters as idlers and dullards: slowness in thinking and acting, hence the inability to take responsibility. Physicians poked fun, for example, at the fact that corpulent people could not understand why they were fat; they insisted that they lived on practically nothing, only eating a small potato and a little piece of meat every day, when, in actual fact, they consumed not insignificant amounts of biscuits, sweets and alcohol (see, for instance, Hallin 1889, Karup 1956). This disparaging approach to obese people is also evident in what they were called. Until at least the 1970s, Swedish medical books often referred to an obese person as "den fete" [the fat one] (Strömbäck 1971); obese people were consequently dehumanised and became their body weight.

Physicians also stated that obese people not only exhibited physical flabbiness, but intellectual lethargy was also a distinguishing characteristic of this group. For who had ever seen a fat genius? Just like "a strong-willed person and a person of action," the great intellectual geniuses were always on the thin side. The benevolence thought to characterise obese people was more down to lethargy than a specific character trait.

For an obese person, besides being associated with traits such as characterless and sluggishness, there was a moral aspect to why they should lose weight, namely the economy. Swedish insurance companies had compiled statistics on how much obesity cost the individual and society. In 1956, the Thule Insurance Company even published a special pamphlet on obesity, in which it was pointed out that obesity was not only the most common and dangerous disease but also the costliest in Sweden. The costs hit not only the obese individual (increased and wasteful food shopping) but also society increased hospital costs and lost working hours) (Karup 1956, Sjövall 1953). The weekly magazines, too, pointed out that there were twice as many obesity sufferers as sick-leavers and ill-health retirees, which, for example, in 1996, resulted in a fall in production that cost Swedish society SEK 6 billion (Aret Runt, no. 51, 1996). 
The moral aspects described above were applicable to both men and women, but one aspect only applied to women. From an obesity perspective, meal habits were seen as a problem, and because women did the cooking, they had to shoulder a lot of the blame for the unhealthy food traditions based on an overabundance of food that caused obesity: "eating too much, too often and too well" (Karup 1956: 10; my translation, Sjövall 1953). Just as bad was the plying of food that women subjected their family members and guests to at "destructive social events" in the form of dinners and coffee gatherings (Sjövall 1953: 125; my translation). These and the other aforementioned moral aspects were primarily presented in the medical books. The weekly magazines kept a much lower moral profile.

\section{Fat and Ugly}

Physicians thought overweight people were "uglified" in every possible way. If having ugly bodies was not enough, so were their movements, and their clothes did not sit right. Losing weight, however, made them thinner and, with that, more beautiful: their skin, eyes and teeth improved. Here women were especially singled out. Young women were thought to very much want to compete with each other for who was the prettiest and the most elegant, which meant being thin, but older women also wished to be attractive; however, this desire proved difficult to achieve when they were menopausal because women were inclined to put on weight. To stay thin and, with that, attractive, this group of women needed to clench their teeth and battle extremely hard (Brown 1951).

The medical profession was, however, split over whether people should lose weight to look good. On the one hand, the vanity of unmarried young women and widows was seen as a powerful stimulus for dieting, and on the other hand, it was not good that women were blindly conforming to the exaggerated thin beauty ideal conveyed by the film and fashion industries, the reason being this ideal was no more consistent with good health as obesity. The ideal was somewhere in between: people feel at their best when they are "amply filled out." Dieting, according to physicians, should primarily be to improve health and must not only be an aesthetical, fashion-oriented issue (Pfannenstill 1901, Dickstone 1948, Ahltorp and Kühnel 1956).

There were, however, shortcuts in the form of corsets, which replaced stays during the nineteenth century, but the former also met with criticism. As a counter to the impracticality of the corset and its detrimental effect on women's freedom and health, dress reform movements came into existence in the Western world; they felt that because men and women were born with the same motor ability, the latter's should not be restricted. In the decades around the turn of the twentieth century, the reform dress was an alternative to more fashion-oriented clothes; it included, along with underwear, both everyday clothes and more glamorous clothes. At first, mainly women who moved in intellectual and artistic circles wore these clothes, but, with time, they spread to other groups (Hammar and Rasmussen 2008).

The corset market must have been booming seeing as ads for this undergarment featured in practically every issue of the weekly magazines from the 
turn of the twentieth century to the 1970s, when this item of clothing disappeared in the wake of the 1968 movement. The arguments for wearing corsets were that they added to the comfort as well as to the pleasure and beauty: "Nothing is more comfortable or pleasurable than a well-fitting corset." There were plenty of corsets to choose from: high and low corsets, long- and short-waist corsets, corsets for broad hips and thin hips, corsets for slender women and "stout" women (Dean 1900); in fact, corsets for all shapes and sizes.

The sales argument that corsets hid women's overweight bodies, thus giving them beautiful figures, continued until the ads stopped running. A typical ad might urge women to think about their figure care because a neglected body made women older and uglier. In this context, figure care meant a Spirella corset could magically get rid of imperfections, make the wearer look younger and bring out "our most beautiful selves." The company even offered prospective customers home visits by a trained Spirella corsetière (Idun-Veckojournalen, no. 7, 1965).

In the weekly magazines, beauty was always given as a reason for dieting: whether it was only losing a few kilos before the start of the swimsuit season or shedding several kilos. People associated thinness with being attractive: being thin and beautiful for both someone else and yourself was deemed important. The beauty reasons for dieting principally had women as their target group. However, from the moment the weekly magazines started to write about dieting, they published before and after pictures of both men and women; in other words, a little picture of the person in question before their diet alongside a large picture of the end result. Here the reader could clearly see the difference. The large picture also emphasised the texts' message about both the health and the beauty transformation that had taken place (see, for example, Må bra, no. 2, 1991 \& no. 2, 2011; Aret Runt, no. 24, 1960 \& no. 18, 1976).

\section{Fat and Unhappy}

The pre-weight-loss psychosocial problems that Banting said he had were also observed in Sweden. Obese people were thought to suffer "from their bodily defect." Overweight children were teased at school, and overweight girls were not asked to dance; instead, they had to sit and watch their thin counterparts take to the floor. Overweight boys were also thought to be affected. A particularly sensitive matter was if they were getting romantic and were met with derision and giggles. Even though the abusive treatment receded with time, the experiences, according to physicians, nevertheless stayed with them and were a reminder of their former clumsiness and ugliness. It was a myth that obesity was associated with cheerfulness; in actual fact, this group was so unhappy, it was overrepresented in the suicide statistics (Sjövall 1953).

The above description of obese people as terribly unhappy is from the 1950s, but it continued into the 2000s. Physicians highlighted at the time that these people were being treated with contempt and condescension in school and overlooked in the jobs market, and even the health-care system was totally prejudiced against obese people. The widespread view was "that fat people had themselves to blame for their predicament and should pull themselves together 
and tackle their problem" (Åberg 2005: 164; my translation). Physicians attested to the relief that came over successful dieters when their feelings of loneliness and insecurity dissipated when they no longer felt socially excluded. A 1980s study showed that successful dieters had twice as many friends as the control group; in other words, they had a better quality of life (Rössner 1988).

A better quality of life was highlighted also in the weekly magazines as a reason for dieting. Instead of sitting at home, feeling dissatisfied with themselves and not feeling seen, their self-confidence grew, and they gained a new life with new opportunities. Besides being fitter and happier, some had children, while others felt more appreciated and braver (see, for example, Må bra, no. 8, $1991 \&$ no. 11, 2001; Aret Runt, no. 31, 2016 \& no. 4, 2001). Apart from improved health, a transformed life was another central theme of the aforementioned dieting genre. Such dieting stories typically began with the protagonist having been overweight already as a child; their excess weight gradually increased, leaving them feeling physically and mentally unwell. Time and again, they tried to lose weight but always failed. Eventually they found the method, with a capital M - usually a diet combined with physical activity - lost 30 to 40 kilos and became beautiful and happy and were full of confidence and belief in the future (see, for instance, Aret Runt, no. 39, 1996; Må bra, no. 1, 2001). Despite setbacks and external and internal doubts, they nevertheless achieved their goal. Thanks to hard work and support from someone who believed in them, these unhappy ducklings were transformed into happy swans thanks to their dieting.

\section{The Weight Attached to Dieting}

This article has aimed to examine the history of Swedish dieting from the introduction in Sweden of William Banting's weight loss treatment to the present day. The article took as its starting point the following question: What were the underlying reasons why people should lose weight? It is clear that Banting's course of treatment kindled the interest of Swedish physicians, who, for instance, praised its scientific claims because it was based on contemporary physiological and medical knowledge. From a biopower perspective, the concept can be described as the technology to which the technique (dieting) was linked.

Already in his pamphlet, Banting put forward two sets of clear reasons (health and psychosocial) why obese people should diet. With obesity came a risk of numerous more or less serious complications. Moreover, obesity had a stigmatising effect. These reasons continued to be invoked throughout the period and were joined by two other sets of reasons: aesthetic and moral; they appeared as early as the end of the nineteenth century and have also been cited ever since. All four sets of reasons appeared, to a lesser or greater extent, in the medical books and the weekly magazines. The aesthetical reasons featured most prominently in the weekly magazines, whereas, naturally enough, the medical books devoted most space to health reasons. When discussing these two sets of reasons, physicians often, however, strayed onto moral reasons. For instance, they noted the lethargy and inability to take responsibility that characterised obese people incapable of losing weight, or they used a condescending tone towards those who 
prioritised the superficial beauty ideal over health reasons. These people were dieting for the wrong reasons. The moralising tone was thus considerably more prominent in the medical books than in the weekly magazines.

The derision and insults obese people endured, making their lives miserable because they could not participate in society in the same way as thin people, were highlighted as the psychosocial reason. Dieting was here portrayed, mostly in the weekly magazines but also in the medical books, as nothing short of a miracle. If only you became thin, your life would change and you would be happy. There are so many of these dieting stories in the weekly magazines that they constitute their own genre. The stories follow the same structure: the dieters' journey from misery to success contains themes, such as misfortune, struggle, health benefits, beauty, social acceptance and happiness. Considering how often the concept was repeated, the readers must have been hugely interested in acquainting themselves with these themes and their moral that the suffering caused by taking tricky and difficult paths can be turned into happiness. Sandberg (2004), too, in her aforementioned study, drew attention to the dieting stories. She calls them success stories that get their dramaturgy from the fairy tale where the prince and princess, after encountering many trials and tribulations, get married in the end and live happily ever after. In these stories, it is, however, principally the beauty reasons that are used for why women should diet, whereas for men, it is the health reasons. Sandberg's findings correspond to this study's regarding the reasons invoked for why women should diet, whereas the health reasons apply to both genders. Moreover, for both men and women, the psychosocial reasons are embedded in a similar dramaturgy.

Narration and stories are a central cultural phenomenon of the history of mankind and have filled many important functions in our lives and our development. Stories have a purpose - they are not told and retold by accident (Bamberg 2011). Because they speak to our emotions, stories can penetrate and affect us differently than a factual text, such as a medical book, and can therefore have a greater impact. Besides the sales of single copies of weekly magazines, stories are, from a biopower perspective, an effective technique for steering the individual towards the desired behaviour of not eating excessively and maintaining their normal weight. This is because biopower not only targets people's reason and rationality but also engages their emotions (Coll 2013), a longing to be, above all, thin and, with that, to belong but also to be in good health.

Dieting, in gender terms, went from a male preserve to something that women increasingly did. As previously mentioned, one difference was, however, that the view was taken that principally women should diet for beauty reasons, whereas for men, it was mainly for health reasons. This became ever clearer the longer time went on. At the beginning of the twentieth century, the aesthetical reasons even applied to men, but these disappeared over time. Moreover, women were depicted as governed more by their emotions than men; they comfort ate and taught their children to do the same. Further, they were more receptive to, and more easily swayed by, the beauty ideal.

Throughout the period, there were thus aesthetical, health, psychosocial and moral reasons why people should diet. What changed was that particularly the 
weekly magazines used less explicitly the reasons to support their argumentation. They appear to be a given, and dieting, or trying to diet, is something you simply do, a matter of course. Foucault's concept of governmentality serves here to enlighten us. Governmentality, or governmental rationality, as it is sometimes referred to, is, according to Foucault, something that acts as a complement to disciplinary power and biopower. An important starting point for this perspective is that the individual will ideally make the right choice and thus control themselves so it benefits both them and society (Nilsson 2008). Self-disciplining the body is central to this. That people act on their own volition in accordance with what they deem good and right for them; to find their own ways of improving their lives, whether it be exercising, healthy eating or maintaining weight. In dieting terms, this meant knowing why it was not good to be overweight and acting accordingly. Should a person fail in their attempt or doubt their own ability, physicians and weekly magazines helped out with supportive and inspirational methods, diets and success stories. However, biopower, often in the form of new research findings, was always in the background to, if necessary, warn of the damaging impact of obesity on the individual and society: autonomy and individual responsibility on the one hand and regulating and boundary setting on the other.

To conclude, there are, with all forms of exercising power, whether it be through public corporal punishment, disciplining or biopower, people who have to pay a high price. The fact cannot be ignored that the new thin norm, established at the beginning of the twentieth century, created a new stigmatised group of people who, for various reasons, could not live up to the norm. Previous research has shown the shame, isolation and scorn that this group has endured. It is clear that, above all, medical books, but also weekly magazines, have very much played a part in this by depicting overweight people as sick, stupid, ugly and unhappy.

\section{References}

Åberg H (2005) Bonniers läkarbok (The Bonnier Medical Book). Stockholm: Bonnier.

Ahltorp G, Kühnel P (1956) Kvinnor, se upp: Läkarbok för kvinnor (Women, Beware: A Medical Book for Women). Malmö: Bernces förlag.

Bamberg M (2011) Who am I? Narration and its contribution to self and identity. Theory \& Psychology 21(2): 3-24.

Banting W (1864) Letter on Corpulence: Addressed to the Public, $3^{\text {rd }}$ ed. London: Harrison.

Bolling H (2005) Sin egen hälsas smed: idéer, initiativ och organisationer inom svensk motionsidrott 1945-1981 (The Maker of His Own Health: Ideas, Initiatives and Organizations within Swedish Sports for All between 1945 and 1981). Stockholm: Acta Universitatis Stockholmensis.

Bordo S (1993) Unbearable Weight: Feminism, Western Culture, and the Body. Berkeley: University of California Press.

Brown AW (1951) Konsten att äta sig slank (The Art of Eating Yourself Thin). Stockholm: Lindqvists. 
Coll S (2013) Consumption as biopower: Governing bodies with loyalty cards. Journal of Consumer Culture 13(3): 201-220.

Cotter C (2001) Discourse and Media. In D. Schiffrin, D. Tannen \& H. Hamilton (Eds.), The Handbook of Discourse Analysis. Oxford: Oxford University Press.

Cresswell JW (2012) Educational Research: Planning, Conducting, and Evaluating Quantitative and Qualitative Research, $4^{\text {th }}$ ed. Upper Saddle River, NJ: Pearson Merrill Prentice Hall.

Dean TH (1900) Konsten att bli vacker: en bok för hvarje kvinna (How to Be Beautiful: Nature Unmasked: A Book for Every Woman). Malmö: C.A. Andersson.

Denzin N, Lincoln Y (2008) Collecting and Interpreting Qualitative Materials, $3^{\text {rd }}$ ed. Thousand Oaks, CA: Sage Publications.

Dickstone W (1948) Hemmets illustrerade läkarbok (The Illustrated Medical Book for the Home). Malmö: Malmö Konsttryckanstalt AB.

Edholm E (1880) Bantings kur mot korpulens (Banting's Treatment for Corpulence). Stockholm: P. A. Norstedt \& Söner.

Foxcroft L (2011) Calories \& Corsets: A History of Dieting over 2,000 Years. London: Profile Books.

Harwood V (2009) Theorizing Biopedagogics. In J. Wright \& V. Harwood (Eds.) Biopolitics and the 'Obesity Epidemic': Governing Bodies. New York: Routledge.

Gilman LS (2008) Diets and Dieting: A Cultural Encyclopedia. New York: Routledge.

Hallin OF (1889) Helsan framför allt! Handbok i helso och sjukvårdslära (Health First! A Handbook of Health and Medical Care). Chicago, IL: Swedish Book Co.

Hammar B, Rasmussen P (2008) Underkläder: en kulturhistoria (Underwear: A Cultural History). Stockholm: Signum.

Hasselgren G (2013) Din läkarbok mitt i livet: guiden till hälsa (Your Midlife Medical Book: The Health Guide). Stockholm: Bonnier Fakta.

Josefson A, Tillgren J (1928) Husmoderns läkarbok (The Housewife's Medical Book). Stockholm: Åhlén \& Åkerlunds Förlag.

Karup NB (1956) Fetma: Thulebolagens skriftserie Vår hälsa (Obesity: The Thule Insurance Company's Publication Series Our Health). Stockholm: Thulebolagen.

Lagerlöf HO (1958) Forums stora läkarbok: en handbok för hemmet (Forum's Comprehensive Medical Book: A Handbook for the Home). Stockholm: Forum AB.

Lilja M, Vinterhagen S (2014) Sovereign power, disciplinary power and biopower: Resisting what power with what resistance? Journal of Political Power 7(1): 107126.

Ljunggren J (1999) Kroppens bildning: Linggymnastikens manlighetsprojekt (The Fostering of the Human Body: The Manliness Project of Ling Gymnastics). Eslöv: B. Östlings bokförlag, Symposion.

Nilsson R (2008) Foucault - en introduktion (Foucault: An Introduction). Malmö: Égalité.

Nilsson F (2011) I ett bolster av fett: en kulturhistoria om övervikt, manlighet och klass (In a Cushion of Fat: A Cultural History of Overweightness, Manliness and Class). Lund: Sekel.

Pfannenstill SA (1901) Sjuklig fetma (fettsot) och dess behandling (Morbid Obesity (Overfatness) and Its Treatment). Stockholm: Bille.

Rössner S (1988) Boken om fetma (The Obesity Book). Stockholm: Natur och Kultur.

Sandberg H (2004) Medier och fetma: en analys av vikt (Media \& Obesity: An Analysis of Weight). Lund: Lund University.

Schwartz H (1986) Never Satisfied: A Cultural History of Diets, Fantasies and Fat. New York: Free Press.

Sjövall B (1953) Magra! En bok om fetma (Become Thinner: A Book about Obesity). Stockholm: Wahlström \& Widstrand. 
Sobel J, Maurer D (1999) Weighty Issues: Fatness and Thinness as Social Problems. Hawthorne, NY: Aldine de Gruyter.

Stearns NP (1997) Fat History: Bodies and Beauty in the Modern West. New York: New York University Press.

Stinson K (2001) Women and Dieting Culture: Inside a Commercial Weight Loss Group. New Brunswick, NJ: Rutgers University Press.

Strömbäck P (1971) Läkarboken: modern uppslagsbok $i$ hälso- och sjukvård (The Medical Book: The Modern Encyclopedia of Health and Nursing). Stockholm: Forum.

Thompson JB (1995) The Media and Modernity: A Social Theory of the Media. Stanford, CA: Stanford University Press.

Vester K (2010) Regime change: Gender, class, and the invention of dieting in postbellum America. Journal of Social History 44(1): 39-70.

Zweiniger-Bargielowska I (2010) Managing the Body: Beauty, Health, and Fitness in Britain, 1880-1939. Oxford: Oxford University Press. 